\title{
Load Flow Analysis of Hybrid AC-DC Power System with Offshore Wind Power
}

\author{
Dhua, Debasish; Huang, Shaojun; Wu, Qiuwei
}

\section{Published in:}

Proceedings of ISGT Asia 2017

Link to article, DOI:

10.1109/ISGT-Asia.2017.8378317

Publication date:

2017

Document Version

Publisher's PDF, also known as Version of record

Link back to DTU Orbit

Citation (APA):

Dhua, D., Huang, S., \& Wu, Q. (2017). Load Flow Analysis of Hybrid AC-DC Power System with Offshore Wind Power. In Proceedings of ISGT Asia 2017 IEEE. https://doi.org/10.1109/ISGT-Asia.2017.8378317

\section{General rights}

Copyright and moral rights for the publications made accessible in the public portal are retained by the authors and/or other copyright owners and it is a condition of accessing publications that users recognise and abide by the legal requirements associated with these rights.

- Users may download and print one copy of any publication from the public portal for the purpose of private study or research.

- You may not further distribute the material or use it for any profit-making activity or commercial gain

- You may freely distribute the URL identifying the publication in the public portal 


\title{
Load Flow Analysis of Hybrid AC-DC Power System with Offshore Wind Power
}

\author{
Debasish Dhua, Shaojun Huang, Qiuwei Wu \\ Centre for Electric Power and Energy, Department of Electrical Engineering \\ Technical University of Denmark \\ Elektrovej 325, 2800 Kgs. Lyngby, Denmark \\ debasish.dhua@gmail.com, shuang@elektro.dtu.dk,qw@elektro.dtu.dk
}

\begin{abstract}
The offshore wind power has received immense attention because of higher wind speed and lower opposition for construction. A wide range of combinations of high-voltage ACDC transmission have been proposed for integrating offshore wind farms and long-distance power transmission. This paper is to model such hybrid AC-DC systems including the interfacing converters, which have several control parameters that can change the load flow of the hybrid systems. Then, the paper proposes a Load Flow algorithm based on the Newton-Raphson method, which covers three different section types of the transmission system: the AC parts, the DC parts and the interfacing converters. Finally, this paper validates this algorithm through a detailed case study with a typical hybrid network.
\end{abstract}

Index Terms- Hybrid AC-DC network, Load Flow, NewtonRaphson, Offshore Wind Farm, Voltage Source Converter

\section{INTRODUCTION}

To meet the ever growing energy demand across the world in a sustainable manner, the Offshore Wind Conversion Technology (OWT) is a promising option [1]. It is estimated that, by 2030, the installed wind power capacity will reach up to $300 \mathrm{GW}$ [2-3]. The OWT is becoming popular because of higher wind speeds and lower opposition for construction. The steady wind stream at a greater speed offers competitive load factors to OWT $(39 \%)$ compared to its onshore counterpart $(22 \%)$ [4]. The combination of the interconnected High Voltage AC (HVAC) and High Voltage DC (HVDC) transmission network for integrating offshore wind farms have been widely investigated [2-8].

On the other hand, long distance HVDC transmission proves to be advantageous over HVAC transmission due to the enhanced stability features, e.g., i) instantaneous precise control, ii) flexible connection among different synchronous zones, iii) enhanced transmission distance limit, whereas the reactive power flow due to large cable capacitance in submarine cables limits the maximum transmission distance, iv) capability of providing additional stability to the AC power network by constant frequency control, redistribution of power in the AC system and providing damping [9-15], [17]. Currently, there are three major manufacturers of VSC-HDVC

The work was supported by both the "Rammeaftale vedrtitrende udnyttelse af PowerlabDK's facillteter" project and the "Voltage control on the transmission grid using wind power at other voltage levels (VOLATILE)' project (EU 'ERA-Net Smart Grids Plus'). systems; i.e. HVDC MaxSine by Alstom Grid; HVDC PLUS from Siemens and HVDC Light manufactured by ABB [16].

The classical load flow algorithms, e.g., Newton-Raphson (NR), Fast Decoupled, DC load flow, are popular for estimation of transmission operating state and energy/demand schedule in interconnected AC networks. Whereas, the integration of Conventional Generation Units and Converter-based Generation resources in a hybrid AC-DC network demands more research. This paper is to develop an algorithm applicable to such hybrid networks. The developed load flow algorithm based on NR can be applied to large-scale AC-DC system where Voltage Source Converters (VSCs) have been largely employed.

The paper is organized as follows: Section II develops the model of the hybrid networks with focus on the DC systems and Converter systems; Section III introduces the proposed load flow algorithm with a flowchart diagram; Section $I V$ presents the case study results on a typical AC-DC network; Finally, Section $V$ concludes the paper with future application possibilities of the proposed Unified NR algorithm.

\section{MODELLING OF CONVERTER-HVDC-AC SYSTEM}

The NR method is widely used as a classical tool to calculate the Load Flow in an AC system. The differences in voltage magnitudes and angles between two connecting buses influence the Active (P) and Reactive Power (Q) flow in AC networks. Whereas, the load flow in DC network is governed by the voltage magnitudes at its terminals. In a hybrid AC-DC network, the performance and controllability of the interfacing VSCs play a key role in affecting the Apparent power (S) flow. In modern AC-DC transmission networks, power flows (both Active and Reactive) are largely influenced by Flexible AC Transmission Systems, i.e., Unified Power Flow Controller (UPFC), Static VAR Compensation (SVC), Static Synchronous Compensator (STATCOM) [18-20]. Moreover, in present-time, large scale wind farms need to fulfill a wide range of technical requirements and ancillary services, e.g., fault-ride through (FRT), reactive power supply and frequency-active power control [21]. VSCs at the HVDC terminals have great advantages for instantaneous active-reactive power control and 
support the onshore AC network [22]. Hence, it is of interest to develop an algorithm for load flow analysis of hybrid AC-DC systems by extending the classical NR method.

There are three sets of equalities in a hybrid network. These constraints can be expressed in terms of a set of power flow equalities as, I) Converter power conversion equalities, II) DC power flow equalities, III) AC power flow equalities.

\section{A. Converter power conversion equalities}

From the load flow point of view, there is a generalized configuration that can be applied to both AC and DC system at the junction point, since the converter can be treated as a power injector at either point [8]. For an AC/DC converter, the power flow equation can be expressed as below,

$$
P_{A C, m}+P_{D C, m}+P_{\text {loss }, m}=0
$$

where, $P_{A C, m}$ and $P_{D C, m}$ represent active power flow into the AC system and DC system, respectively; $P_{\text {loss }, m}$ is the active power loss inside $m$-th converter. In case of reactive power flow, such an interactive equation is not applicable, since the HVDC line decouples the reactive power transmission at its terminals. The AC-DC interaction can be elaborated in two segments henceforth.

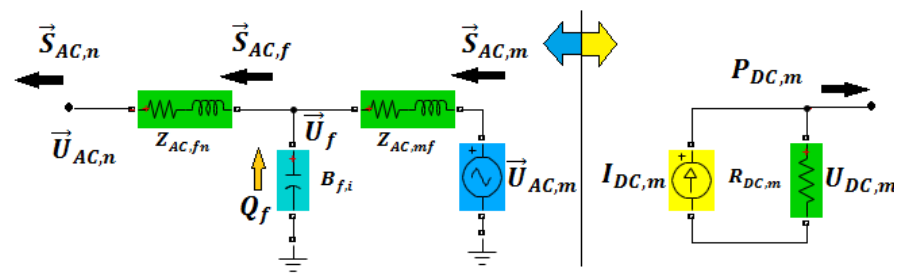

Figure 1 Left: VSC configuration from AC system, Right: VSC configuration from DC system

Observing from the AC power system, $m$-th VSC can be seen as a voltage source with generating voltage $\vec{U}_{A C, m}$ and injecting power $\vec{S}_{A C, m}=P_{A C, m}+j Q_{A C, m}$ towards $n$-th nodal point via the shunt filter nodal point. The inverted AC power from DC sources contains a large Total Harmonic Distortion (THD). Therefore, it is passed through the shunt filters which also can support AC system by compensating (injecting/absorbing) reactive power requirements. In (2)-(5), $G_{A C, m f}+j B_{A C, m f}=1 / Z_{A C, m f}$ is per phase converter admittance as seen from the $\mathrm{AC}$ side and $G_{A C, f n}+j B_{A C, f n}=$ $1 / Z_{A C, f n}$ is per phase admittance of the interconnecting transformer. Finally, the active and reactive power flow balances are expressed in (7) and (8).

$$
\begin{gathered}
P_{A C, m}=U_{A C, m}^{2} G_{A C, m f}- \\
U_{A C, m} U_{A C, f}\left(G_{A C, m f} \cos \left(\delta_{A C, m}-\delta_{A C, m}\right)+\right. \\
\left.B_{A C, m f} \sin \left(\delta_{A C, m}-\delta_{A C, f}\right)\right) \\
Q_{A C, m}=-U_{A C, m}^{2} B_{A C, m f}- \\
U_{A C, m} U_{A C, f}\left(G_{A C, m f} \sin \left(\delta_{A C, m}-\delta_{A C, f}\right)-\right. \\
\left.B_{A C, m f} \cos \left(\delta_{A C, m}-\delta_{A C, f}\right)\right)
\end{gathered}
$$

$$
\begin{gathered}
P_{A C, f}=U_{A C, f}^{2} G_{A C, f n}- \\
U_{A C, f} U_{A C, n}\left(G_{A C, f n} \cos \left(\delta_{A C, f}-\delta_{A C, n}\right)+\right. \\
\left.B_{A C, f n} \sin \left(\delta_{A C, f}-\delta_{A C, n}\right)\right) \\
Q_{A C, f}=-U_{A C, f}^{2} B_{A C, f n}- \\
U_{A C, f} U_{A C, n}\left(G_{A C, f n} \sin \left(\delta_{A C, f}-\delta_{A C, n}\right)-\right. \\
\left.B_{A C, f n} \cos \left(\delta_{A C, f}-\delta_{A C, n}\right)\right) \\
Q_{f}=U_{f}^{2} B_{f, i} \\
P_{A C, m}-P_{l o s s, A C, m f}-P_{l o s s, A C, f n}-P_{A C, n}=0 \\
Q_{A C, m}+Q_{f}-Q_{A C, n}=0
\end{gathered}
$$

\section{B. DC power flow equalities}

As indicated in Figure 1, the Converter system can be considered as a constant current source from the DC system with an injection current $I_{D C, m}$ by $m$-th converter into the DC system. $Y_{D C, m p}$ is the DC bus admittance between $m$-th and $p$ th $\mathrm{DC}$ node. Hence, the total active power injected by $m$ - $t h$ node into the DC system can be expressed as (10).

$$
\begin{gathered}
I_{D C, m}=\sum_{p=1}^{n_{D C}} Y_{D C, m p}\left(U_{D C, m}-U_{D C, p}\right) \\
P_{D C, m}=U_{D C, m} I_{D C, m}+P_{l o s s, D C, m p}
\end{gathered}
$$

The offshore wind turbines produce AC power which is then converted to high voltage DC power and transmitted through the long distance submarine cable to the onshore transformer. In further, the transmitted DC power is inverted to $\mathrm{AC}$ power by the onshore converter system and fed into the main land AC grid. Hence, the two terminal DC link needs to be further analyzed as in [23].
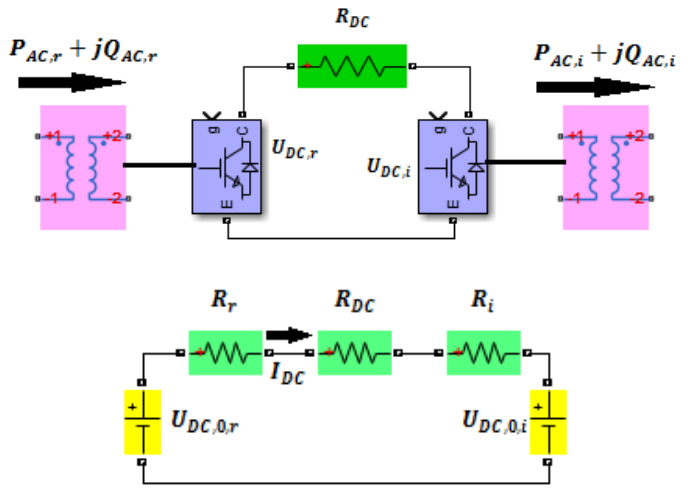

Figure 2 a) Two terminal model of HVDC transmission link, b) Close loop circuit representation of two-terminal DC link

To analyze the steady state converter operation, the following assumptions can be made for further detailing of the load flow constraints, a) the AC terminal voltages are balanced and sinusoidal, b) the rectifier and inverter are capable of ideal AC-DC conversion and c) DC current does not contain any AC component. If the $\mathrm{AC}$ to $\mathrm{DC}$ rectifier terminal is denoted by ' $\mathrm{r}$ ' and $\mathrm{DC}$ to $\mathrm{AC}$ inverter terminal is denoted by ' $i$ ', the Kirchhoff's laws can be separately expressed for Rectifier and Inverter Terminals. 
Rectifier and Inverter Equations

$$
\begin{gathered}
U_{d, 0, r}=k n_{r} U_{A C, r} \\
U_{d, r}=U_{d, 0 . r} m_{r}-R_{r} I_{d, r} \\
P_{r}=U_{d, r} I_{d, r} \\
Q_{r}=U_{d, r} I_{d, r} \tan \varphi_{r} \\
U_{d, 0, i}=k n_{i} U_{A C, i} \\
U_{d, i}=U_{d, 0 . i} m_{i}-R_{i} I_{d, i} \\
P_{i}=U_{d, i} I_{d, i} \\
Q_{i}=U_{d, i} I_{d, i} \tan \varphi_{i}
\end{gathered}
$$

where $U_{d, 0, r}, U_{d, 0, i}$ are the ideal no-load DC voltage after conversion of the per phase $\mathrm{AC}$ voltage $U_{r}$ at the rectifier terminal and $U_{i}$ at the inverter terminal respectively, $\mathrm{k}=$ $3 \sqrt{2} / \pi$ is the AC/DC conversion factor, $m_{r}, m_{i}$ are the rectifier and inverter modulation indices, respectively. $R_{r}, R_{i}$ represent the equivalent commutating resistance of the rectifier and inverter, respectively. Since the losses at the transformers and converters are neglected hence, $P_{r}=P_{A C, r} \& Q_{r}=Q_{A C, r}$ and $P_{i}=P_{A C, i} \& Q_{i}=Q_{A C, i}$.

The active power flow direction solely depends on the direction of current $I_{D C}$ flowing in the DC network, which depends on the voltage level at the two terminals of the DC network. The reactive power is either injected into the AC network or absorbed from the AC network at the terminals since there is no reactive power transmission through the DC network. $\varphi_{r}, \varphi_{i}$ are the power factor at the rectifier and inverter terminals respectively connected to the $\mathrm{AC}$ terminal.

\section{Line equation}

The line current through the DC link between the rectifier and inverter is expressed as (16). $I_{D C}=I_{D C \text {,rect }}=I_{D C \text {, inv }}$ and $R_{D C}$ is the DC line resistance.

$$
I_{D C}=\frac{U_{d, r}-U_{d, i}}{R_{D C}}
$$

\section{AC power flow equality equalities}

The HVDC network exchanges power with the connected onshore AC network. Therefore, the generation, demand and injection (converter terminals) of both active and reactive power for each AC bus can be expressed as (20) and (21).

$$
\begin{aligned}
& \sum_{k \in m_{n_{A C}}} P_{G k}-\sum_{k \in m} P_{L k}+\sum_{k \in m} P_{C o n v, k} \\
& =\sum_{n=1} U_{A C, m} U_{A C, n}\left[G_{A C, m n} \cos \left(\delta_{A C, m n}\right)\right. \\
& \left.+B_{A C, m n} \sin \left(\delta_{A C, m n}\right)\right]
\end{aligned}
$$

$$
\begin{aligned}
& \sum_{k \in m_{n_{A C}}} Q_{G k}-\sum_{k \in m} Q_{L k}+\sum_{k \in m} Q_{C o n v, k} \\
& =\sum_{n=1} U_{A C, m} U_{A C, n}\left[G_{A C, m n} \sin \left(\delta_{A C, m n}\right)\right. \\
& \left.-B_{A C, m n} \cos \left(\delta_{A C, m n}\right)\right]
\end{aligned}
$$

where $P_{C o n v, k}$ and $Q_{C o n v, k}$ are the generation of Active and Reactive power $\left(P_{\text {rect } / i n v, k}\right.$ and $\left.Q_{\text {rect } / i n v, k}\right)$ at the converter connecting node $k$ if connected to the VSC. $P_{G K} \& Q_{G K}$ are generations and $P_{L k} \& Q_{L k}$ are the consumption of Active and Reactive power by the Load at node $k$.

\section{LOAD FLOW ALGORITHM BASED ON NEWTON-RAPHSON METHOD}

The Unified-NR Algorithm is developed on the basis of combination of NR-AC and NR-DC algorithms as discussed in Section II. The objective of this algorithm is to determine the load flow in a hybrid transmission system. This algorithm treats the NR-AC and NR-DC mismatch functions simultaneously and solves the Jacobians iteratively.

The NR-AC mismatch functions are a set of non-linear equations whereas the NR-DC mismatch functions are linear equalities. Since, the non-linear and linear equations are solved and fed-into each other synchronously, it is named as the Unified NR Algorithm. To illustrate the Unified NR algorithm, a flowchart is shown in Figure 3.

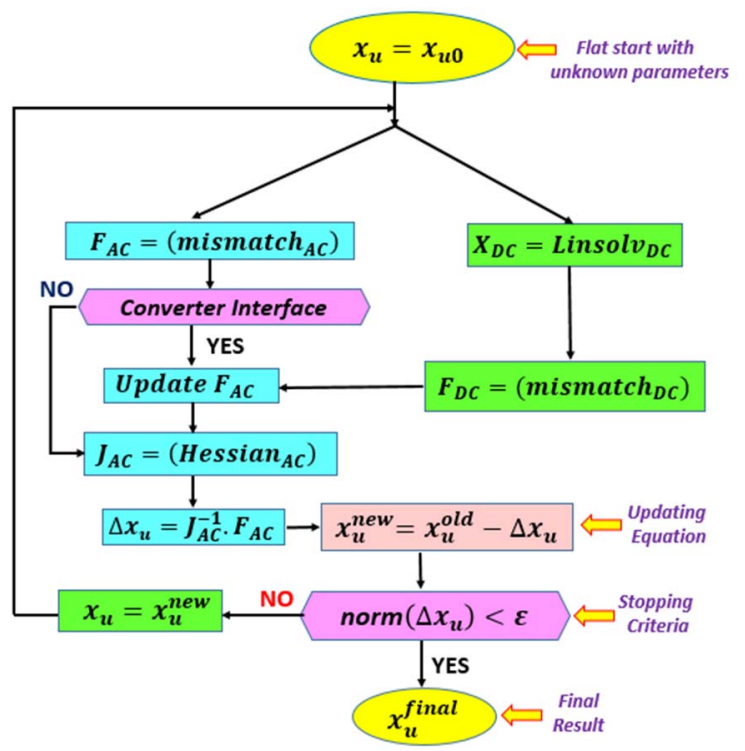

Figure 3. The flowchart of Unified NR algorithm

The Unified NR Algorithm begins with the AdmittanceBus information and voltage-angle data of PV Bus and Slack Bus. The iterative part of the flowchart is described below,

Step I Flat start with unknown voltage-angle information for both AC and DC Buses.

Step II (a) Solve the AC mismatch functions, (b) Solve simultaneous equations for interconnected DC network to determine DC bus voltages. 
Step III Solve DC mismatch functions and update activereactive power injections to $\mathrm{AC}$ buses if there is any converter interface.

Step IV Form the Hessian matrix.

Step V Determine the unknown parameters and update until the stopping criteria are met.

\section{CASE STUDY}

To test the effectiveness of the Unified NR algorithm for load flow analysis of a hybrid system, the example network in Figure 4 is used. This entire network is composed of four sections, a) Interconnected Onshore AC network (in Red), b) Offshore Wind Farm (in Blue), c) Interfacing HVDC network (in Black), d) Interfacing HVAC network (in green). For this typical hybrid system, the types of buses are listed in Table 1 .

Table 1 (Bus Type Data)

\begin{tabular}{|l|l|}
\hline Bus Type & Bus Number (B) \\
\hline Slack Bus & Bus 1 \\
\hline PV Bus & Bus 4, 6 \\
\hline PQ Bus & Bus 2, 3, 5 \\
\hline DC Bus & Bus 7, 8, 9 (converter terminal) \\
\hline
\end{tabular}

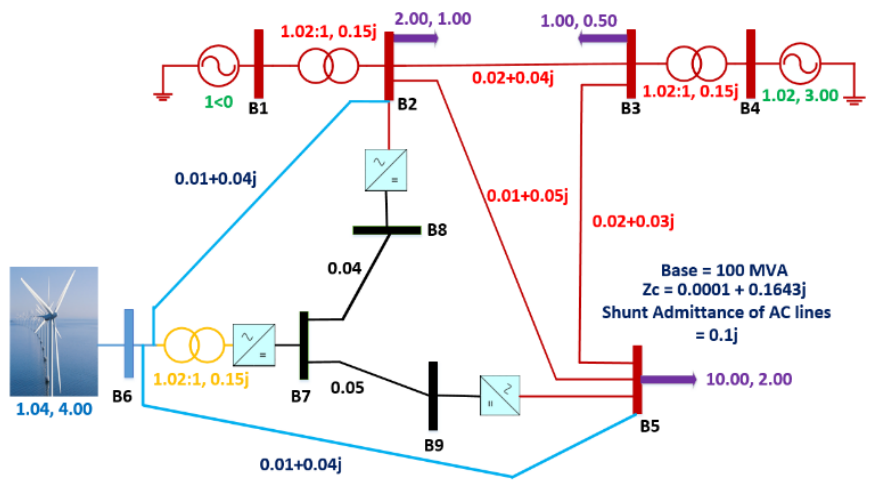

Figure 4. A typical hybrid AC-DC network and Offshore Wind Farm

\section{A. Case I}

In this case, the Classical NR method is run by considering the all AC system. The Offshore Wind Power is directly transmitted to the Onshore AC network through B6-B2 \& B6$\mathrm{B} 5$ (in Blue) HVAC cables, the interference of converter buses i.e. B7, B8, B9 (in Black) is completely ignored in load flow calculations. After 5 iterations (with $\varepsilon=10^{-5}$ ), the algorithm converges. The voltages and angles in all buses are obtained and listed below. The Load flow Result for Case I is shown in Table 2.

Table 2 (Load Flow Results of Case I)

\begin{tabular}{|c|c|c|}
\hline Bus & Voltage V (p.u.) & Angle $\boldsymbol{\theta}$ (p.u.) \\
\hline 1 & 1.000 & 0.000 \\
\hline 2 & 0.870 & -0.287 \\
\hline 3 & 0.858 & -0.319 \\
\hline 4 & 1.020 & 0.208 \\
\hline 5 & 0.809 & -0.435 \\
\hline 6 & 1.040 & -0.152 \\
\hline
\end{tabular}

In Case I, Active-Reactive power flow is fixed once the system parameters (Admittance-Bus) are decided. Therefore, it is not possible to achieve further load flow controllability and demonstrate the additional ancillary services provided by the large offshore wind farm.

\section{B. Case II}

Here, the Offshore Wind Power is transferred though the VSC-HVDC system. To implement the Unified NR algorithm, Offshore AC Bus B6 is connected to the inverter Bus B7 and thereafter, it is transferred to the Onshore Network via the HVDC lines B6-B7 \& B6-B8 (in Black). The HVAC Offshore transmission lines, i.e., B6-B2 \& B6-B5 (in Blue), are removed in this case.

A set of DC link characteristics, which are applied on the developed network for analysis in this case, are listed in Table 3. In Case II, the converter modulation indices (Case II-A) and power factor angles (Case II-B) are varied in three different sub-cases to indicate their effect on PV and PQ bus voltages (V) and angles $(\theta)$ and subsequently Active \& Reactive Power flow in connecting network.

After 5 iterations (with $\varepsilon=10^{-5}$ ), the algorithm converges. The voltages and angles of all buses are obtained and listed below in Table 4 and Table 5 for all three-sub cases for Case II- $A$ and Case II- $B$, respectively.

Table 3 (DC link characteristics)

\begin{tabular}{|c|c|}
\hline Characteristics & Symbol and Data \\
\hline Converter Reactance & $Z_{C}=0.0001+\mathrm{j} 0.16$ (identical) \\
\hline DC line Impedance & $Z_{D C, 78}=0.04$ and $Z_{D C, 79}=0.05$ in p.u. \\
\hline Converter Trans. Ratio & $n_{r}=n_{i}=1$ \\
\hline Converter Modulation & $m_{r}=1.0,0.98,0.95$ \\
Indices & $m_{i}=1.0,0.98,0.95$ \\
\hline Power Factor Angle & $\varphi_{r 6}=18^{\circ}, 11^{\circ}, 18^{\circ}$ \\
& $\varphi_{i 7}=25^{\circ}, 18^{\circ}, 11^{\circ}$ \\
& $\varphi_{i 8}=25^{\circ}, 18^{\circ}, 25^{\circ}$ \\
\hline
\end{tabular}

In Case II-A, the Unified NR algorithm is run with different modulation indices with fixed power factor angles $\left(\varphi_{r 6}=\right.$ $\left.18^{\circ}, \varphi_{i 7}=25^{\circ}, \varphi_{i 8}=25^{\circ}\right)$.

Table 4 (Load Flow Results in Case II-A)

\begin{tabular}{|c|c|c|c|c|c|c|}
\hline Bus & \multicolumn{2}{|c|}{$\begin{array}{c}\text { Case II - A (i) } \\
m_{r}=\mathbf{1 . 0} \\
m_{\boldsymbol{i}}=\mathbf{1 . 0}\end{array}$} & \multicolumn{2}{c|}{$\begin{array}{c}\text { Case II - A (ii) } \\
m_{r}=\mathbf{0 . 9 5} \\
m_{\boldsymbol{i}}=\mathbf{0 . 9 5}\end{array}$} & \multicolumn{2}{c|}{$\begin{array}{c}\text { Case II - A (iii) } \\
m_{r}=\mathbf{0 . 9 8} \\
m_{i}=\mathbf{0 . 9 5}\end{array}$} \\
\cline { 2 - 8 } & $\mathbf{V}$ (p.u.) & $\mathbf{\theta}$ (p.u) & $\mathbf{V}$ (p.u.) & $\boldsymbol{\theta}$ (p.u) & V (p.u.) & $\boldsymbol{\theta}$ (p.u) \\
\hline 1 & 1.000 & 0.000 & 1.000 & 0.000 & 1.000 & 0.000 \\
\hline 2 & 0.978 & -0.274 & 0.840 & -0.369 & 1.053 & -0.128 \\
\hline 3 & 0.960 & -0.313 & 0.818 & -0.432 & 1.035 & -0.155 \\
\hline 4 & 1.020 & 0.153 & 1.020 & -0.124 & 1.020 & 0.275 \\
\hline 5 & 0.923 & -0.424 & 0.756 & -0.583 & 1.010 & -0.251 \\
\hline 6 & 1.040 & 0.035 & 1.040 & 0.060 & 1.040 & -0.158 \\
\hline 7 & 1.400 & - & 1.316 & - & 1.375 & - \\
\hline 8 & 1.347 & - & 1.266 & - & 1.263 & - \\
\hline 9 & 1.348 & - & 1.267 & - & 1.264 & - \\
\hline
\end{tabular}


In Case II-B, the power factor angles are changed in three subcases with modulation indices remains same as $\left(m_{r}=\right.$ $\left.0.98 ; m_{i}=0.95\right)$ in all three sub-cases.

Table 5 (Load Flow Results in Case II-B)

\begin{tabular}{|c|c|c|c|c|c|c|}
\hline Bus & \multicolumn{2}{c|}{$\begin{array}{c}\text { Case II - B (i) } \\
\varphi_{r 6}=\mathbf{1 8}^{\circ}\end{array}$} & \multicolumn{2}{c|}{$\begin{array}{c}\text { Case II - B (ii) } \\
\varphi_{r 6}=\mathbf{1 1}^{\circ}\end{array}$} & \multicolumn{2}{c|}{$\begin{array}{c}\text { Case II - B (iii) } \\
\varphi_{r 6}=\mathbf{1 8}^{\circ}\end{array}$} \\
& $\begin{array}{c}\varphi_{i 7}=25^{\circ} \\
\varphi_{i 8}=25^{\circ}\end{array}$ & \multicolumn{2}{c|}{$\begin{array}{c}\varphi_{i 7}=\mathbf{1 8}^{\circ} \\
\varphi_{i 8}=\mathbf{1 8}^{\circ}\end{array}$} & \multicolumn{2}{c|}{$\begin{array}{c}\varphi_{i 7}=\mathbf{1 1}^{\circ} \\
\varphi_{i 8}=25^{\circ}\end{array}$} \\
\cline { 2 - 8 } & $\mathbf{V}$ (p.u.) & $\boldsymbol{\theta}$ (p.u) & $\mathbf{V}$ (p.u.) & $\boldsymbol{\theta}$ (p.u) & V (p.u.) & $\boldsymbol{\theta}$ (p.u) \\
\hline 1 & 1.000 & 0.000 & 1.000 & 0.000 & 1.000 & 0.000 \\
\hline 2 & 1.053 & -0.128 & 1.003 & -0.134 & 0.999 & -0.133 \\
\hline 3 & 1.035 & -0.155 & 0.986 & -0.166 & 0.989 & -0.166 \\
\hline 4 & 1.020 & 0.275 & 1.020 & 0.287 & 1.020 & 0.285 \\
\hline 5 & 1.010 & -0.251 & 0.954 & -0.269 & 0.962 & -0.270 \\
\hline 6 & 1.040 & -0.158 & 1.040 & -0.158 & 1.040 & -0.158 \\
\hline 7 & 1.375 & - & 1.375 & - & 1.375 & - \\
\hline 8 & 1.263 & - & 1.263 & - & 1.263 & - \\
\hline 9 & 1.264 & - & 1.264 & - & 1.264 & - \\
\hline
\end{tabular}

The advantages of additional controllability in the Power Flow technique are clearly observed in load flow results from Table 4 and Table 5. According to Case $I I-A$, the voltages and angles of all Buses (AC and DC) are modified by changing the rectifier and inverter modulation indices. The active and reactive power references can be adjusted by controlling the converter operating power factor angles. The power factor angles can control the power flow in the AC network without altering the DC network parameters. From Table 5, it can be seen that the DC bus voltages remain unchanged in all three subcases of Case II-B.

\section{CONCLUSION}

The Unified NR algorithm provides an opportunity for load flow analysis of hybrid AC-DC systems without altering the simplicity and robustness of the existing Classical NewtonRaphson load flow algorithm. In this new algorithm, the AC mismatch functions can be suitably updated by exchanging power at the converter-interfacing Buses and thereafter follow the iterative process till converging (mismatch tends to zero). The modeling of the converter-modulation index control is established in this paper and the added benefits (additional flexibility to the system) of this control method are shown though the Case Study.

This algorithm is adaptive to large scale AC-DC networks with/without Offshore Wind Farm integrations, which will be further studied in the future work. In addition, it is also possible to implement this algorithm for Optimal Power Flow, Load Flow Congestion studies, Unity Dispatch and Static Security Assessment problems of hybrid network.

\section{REFERENCES}

[1] Fujin Deng, Zhe Chen, "Design of Protective Inductors for HVDC Transmission Line Within DC Grid Offshore Wind Farms", IEEE Transactions on Power Delivery - 2013, Volume 28, Issue 1, pp.75-83.

[2] S. K. Chaudhary, R. Teodorescu, and P. Rodriguez, "Wind Farm Grid Integration Using VSC Based HVDC Transmission-An Overview," 2008 IEEE Energy 2030 Conference - 2008, pp. 493-499.

[3] Pinaki Mitra, Lidong Zhang, Lennart Harnefors, "Offshore Wind Integration to a Weak Grid by VSC-HVDC Links Using PowerSynchronization Control: A Case Study", IEEE Transactions on Power Delivery, Vol. 29, No. 1, February 2014.
[4] [Online]http://www.ewea.org/fileadmin/files/library/publications/report s/EY-Offshore-Wind-in-Europe.pdf

[5] Hao Chen, Michael H. Johnson, Dionysios C. Aliprantis, "LowFrequency AC Transmission for Offshore Wind Power", IEEE Transactions on Power Delivery, Vol 28, No. 4, October 2013.

[6] Nathalie Holtsmark, Himanshu J. Bahirat, Marta Molinas, Bruce A. Mork and Hans Kr. Høidalen, " An All-DC Wind Farm With SeriesConnected Turbines: An Alternative to the Classical Parallel AC Model?", IEEE Transactions on Industrial Electronics, Vol. 60, No. 6, June 2013.

[7] Wu Chen, Alex Q. Huang, Chushan Li, Gangyao Wang and Wei Gu, "Analysis and Comparison of Medium Voltage High Power DC/DC Converters for Offshore Wind Energy Systems", IEEE Transactions on Power Electronics, Vol. 28, No. 4, April 2013.

[8] Jun Cao, Wenjuan Du, Haifeng F. Wang and S. Q. Bu, "Minimization of Transmission Loss in a Meshed AC/DC Grids With VSC-MTDC Networks", IEEE Trans. on Power Systems, Vol. 28, No. 3, August 2013.

[9] C.Meyer,M. Hoing, A. Peterson, and R. W. De Doncker, "Control and Design of DC Grids for Offshore Wind Farms," IEEE Trans. Ind. Appl., vol. 43, no. 6, pp. 1475-1482, Nov./Dec. 2007.

[10] Botta Ravi, Venkata Rama Raju Rudraraju, C. Nagamani, G. Saravana Ilango, "Direct Load Flow Algorithm to Evaluate Performance of Offshore Wind Farm Distribution Systems" 2015 International Conference on Energy Systems and Applications (ICESA 2015)

[11] T. Kulworawanichpong, "Simplified newton raphson power flow method, "International Journal of Electrical Power \& Energy Systems vol. 32, no.6, pp.551-558, July 2010.

[12] B. Stott and O. Alsac, "Fast decoupled load flow," IEEE Trans. Power Apparatus Systems, vol. 93, pp. 859-869, May/June 1974.

[13] [Online] "Why HVDC", ABB http://new.abb.com/systems/hvdc/whyhvdc

[14] [Online] Technical Advantages" of HVDC Transmission by ABB http://new.abb.com/systems/hvdc/why-hvdc/technical-advantages

[15] N. M. Kirby, L. Xu,M. J. Luckett, and W. Siepmann, "HVDC transmission for large offshore wind farms," IET Power Eng. J., vol. 16, no.3, pp. 135-141, Jun. 2002.

[16] H M Mesbah Maruf, Bhaskar Mitra, Prasanth Kumar Sahu, M Manjrekar, B. H. Chowdhury, "Hybrid High Voltage AC/DC System for Interfacing Off-shore Power Generations with On-Shore Grid", Proceedings of IEEE Southeastcon - 2016, Volume 2016-, pp. 7506707

[17] A. Beddard, W. Wang, M. Barnes, P.R. Green, A. Beddard, T.C. Green, "Impact of Parameter Uncertainty on Power Flow Accuracy in Multiterminal Systems", IEEE Power and Energy Society General Meeting 2016, Volume 2016, pp. 7741425

[18] Bin Lu, Boon Teck Ooi, "Unified Power Flow (UPFC) under Nonlinear Control", Pcc-osaka 2002: Proceedings of the Power Conversion Conference-osaka 2002, Vols I - Iii - 2002, Volume 3, pp. 1118-1123

[19] L. Gyugyi, C.D. Schauder, S. L. Williams, T.R. Rietman, D.R. Torgerson, A.Edris, "The Unified Power Flow Controller: A New Approach to Power Transmission Control", IEEE Transactions on Power Delivery, Vol. 10, No. 2, April 1995.

[20] Tatsuhito Nakajima, Shoichi Irokawa, "A Control System for HVDC Transmission by Voltage Source Converters", 1999 IEEE Power Engineering Society Summer Meeting. Conference Proceedings - 1999, Volume 2, pp. 1113-19 vol.2

[21] Ioannis D. Margaris, Anca D. Hansen, Poul SØrensen and Nikolaos D. Hatziargyriou, "Illustration of Mordern Wind Turbine Ancillary Services", Energies - 2010, Volume 3, Issue 6, pp. 1290-1302.

[22] A. D. Hansen, P Sørensen, F Iov, F Blaabjerg. "Centralised power control of wind farm with doubly-fed induction generators" Renew. Energy 2006, 31, 935-951.

[23] A. Panosyan, B. R. Oswald, "Modified Newton-Raphson Load Flow Analysis For Integrated AC/DC Power Systems", Upec 2004: 39th International Universitities Power Engineering Conference, Vols 1-3, Conference Proceedings - 2005, pp. 1223-1227. 